\title{
Topical Corticosteroids Misuse: A Burning Issue
}

\author{
Neupane S \\ Department of Dermatology, Gandaki Medical College, Pokhara

\begin{abstract}
Since the introduction of hydrocortisone into dermatology, a tremendous development has occurred in the field of topical corticosteroids. With the growing use of topical corticosteroids, a serious concern for its misuse is to be highlighted. This matter is of a great concern. Proper guidelines and legislation on the use of topical corticosteroids are warranted to combat this serious issue.

Key words: Glucocorticoids; Hydrocortisone; Nepal; Nonprescription drugs
\end{abstract}

T he history of use of topical corticosteroid into dermatology started from Hydrocortisone which was initially named as "compound F" in 1952. ${ }^{1}$ Since then, there has been a tremendous development in the field of topical corticosteroids and today we have different classes of topical corticosteroids in our dermatological therapeutic armamentarium. Topical corticosteroids have been used in dermatological practices for various uses such as anti-inflammatory, anti-pruritic, or other actions.

With its growing use, a serious concern for misuse is to be highlighted and addressed. Even in Western country where few milder topical corticosteroids are available as over the counter drugs, corticosteroids' misuse has posed serious problems. ${ }^{2}$ Topical corticosteroids can result in both local as well as systemic adverse effects.

Misuse of topical corticosteroid is of a great concern in the Indian subcontinent including Nepal. ${ }^{3,4,5}$ Studies have shown that the most common cause of misuse is its use for fairness purpose. ${ }^{3,5}$ Hence, proper guidelines and strict legislation on the use of topical corticosteroids, limitation on the over the counter availability; mandating a prescription preferably by dermatologists will definitely help to combat this serious issue.

Financial support: None.

Conflict of interest to disclosure: None declared.

Address of Correspondence:

Dr. Saraswoti Neupane, MD

Professor

Department of Dermatology

Gandaki Medical College, Pokhara, Nepal

E-mail: sarunpn@gmail.com

\section{References}

1. Sulzberger MB, Witten VH. The effect of topically applied compound F in selected dermatoses. J Invest Dermatol. 1952; 19:101-2. https://doi.org/10.1038/ jid.1952.72

2. Rogers PJ, Wood SM, Garrett EL, Krykant SP, Haddington NJ, Hayhurst J, et al. Use of non-prescription topical steroids: Patients' experiences. $\mathrm{Br} J$ Dermatol. 2005;152:1193-8. https://doi.org/10.1111/j.1365-2133.2005.06513.x

3. Saraswat A, Lahiri K, Chatterjee M, Barua S, Coondoo A, Mittal A, et al. Topical corticosteroid abuse on the face: A prospective, multicenter study of dermatology outpatients. Indian J Dermatol Venereol Leprol 2011;77:160-6.

4. Jha AK, Karki S, Jha SM. Topical Corticosteroid Abuse in Nepal: Scenario. In: Lahiri K. (eds.) A Treatise on Topical Corticosteroids in Dermatology. Singapore: Springer; 2018 May.p.189-96.https://doi. org/10.1007/978-981-10-4609-4_18

5. Kumar A, Neupane S, Shrestha PR, Pun J, Thapa P, Manandhar $M$, et al. Pattern and predictors of topical corticosteroid abuse on face: A study from Western Nepal. Res J Pharm Biol Chem Sci. 2015;6:1154-9.

Submitted: $1^{\text {st }}$ February 2019

Accepted: $7^{\text {th }}$ February 2019

Published: $31^{\text {st }}$ March 2019

How to cite this article

Topical corticosteroids misuse: A burning issue. Neupane S. Nepal Journal of Dermatology, Venereology and Leprology. 2019;17(1):1. doi: http://dx.doi.org/10.3126/njdvl.v17i1.23116

\section{(c) (i)}

Licensed under CC BY 4.0 International License which permits use, distribution and reproduction in any medium, provided the original work is properly cited. 